\title{
Recruitment, survival, and parasitism of monarch butterflies (Danaus plexippus) in milkweed gardens and conservation areas
}

\author{
Emily A. Geest ${ }^{1} \cdot$ L. LaReesa Wolfenbarger ${ }^{1}$. John P. McCarty ${ }^{1}$
}

Received: 10 July 2018 / Accepted: 24 October 2018 / Published online: 2 November 2018

(c) The Author(s) 2018

\begin{abstract}
Monarch butterflies (Danaus plexippus) are suffering from declining populations and conservationists have encouraged planting milkweed gardens in urban and suburban landscapes to help offset habitat loss across the breeding range. The effectiveness of gardens as a conservation strategy depends on their ability to attract ovipositing adults and the survival of monarch larvae in these gardens. Larvae are susceptible to a variety of predators as well as to parasitism by a tachinid fly (Lespesia archippivora) and a protozoan parasite (Ophryocystis elektroscirrha) which cause lethal or sublethal effects, yet the severity of these risks in gardens is not well understood. We compared egg abundance and larval survival in traditional conservation areas to gardens that incorporated milkweed to attract monarchs. Additionally, we collected late instar larvae and reared them in the lab to compare parasitism rates between monarch gardens and conservation areas. Both gardens and conservations sites varied widely in recruitment and survival of monarchs and there were no significant differences between the garden and conservation sites. Tachinid fly parasitism ranged from 30\% of larvae from conservation sites in 2016 to 55\% of larvae from gardens in 2017, but did not differ between the two categories of sites. Parasitism by O. elektroscirrha was detected in fewer than $2 \%$ of larvae. The density of milkweed had no effect on the number of monarch eggs in conservation areas or gardens in either year. Milkweed density had no effect on tachinid parasitism in conservation areas but had a significant effect in gardens with lower numbers of milkweed stems increasing tachinid parasitism in 2016. Gardeners planted a variety of species of milkweed and Asclepias syriaca was the most commonly used host plant for monarch larvae (85\%). Overall, our results suggest that milkweed gardens have the potential to contribute to successful monarch reproduction. However, the variation among sites and the lack of recruitment from some gardens emphasizes that the realization of this potential contribution will depend on the quality of gardens.
\end{abstract}

Keywords Monarch butterfly $\cdot$ Danaus plexippus $\cdot$ Survival $\cdot$ Parasitoids $\cdot$ Lespesia archippivora $\cdot$ Conservation . Milkweed gardens

This work is derived from the master's thesis completed by EAGeest but has not otherwise been published

Electronic supplementary material The online version of this article (https://doi.org/10.1007/s10841-018-0102-8) contains supplementary material, which is available to authorized users.

John P. McCarty

jmccarty@unomaha.edu

1 Department of Biology, University of Nebraska Omaha, 6001 Dodge St., Omaha, NE 68182, USA

\section{Introduction}

Monarch butterflies (Danaus plexippus) have suffered severe population declines and are of increasing conservation concern (Marini and Zalucki 2017; Pleasants et al. 2017). Considerable attention has been focused on the largest and most well-known eastern population of monarchs that is known for migrating annually between Mexico and the Midwestern United States and southern Canada (Altizer et al. 2000; Shahani et al. 2015). During this migration, up to four generations of monarchs can occur. The first generation has overwintered in Mexico, breeds and moves north into Texas to oviposit. Each subsequent generation moves further north until the final generation emerges in late summer and early fall. This final generation is the migratory generation 
that moves from southern Canada and the northern United States back to Mexico where they overwinter (Oberhauser et al. 2017b).

During their annual cycle monarchs encounter multiple threats contributing to their decline, including habitat loss and fragmentation in their breeding range (Gustafsson et al. 2015). For reproduction monarchs depend on the availability of milkweed (Asclepias spp.) as their only larval host plant, and access to nectar producing plants for adults (Zalucki and Suzuki 1987; Oberhauser et al. 2001). Historically, milkweed and nectar producing flowers existed in continuous grasslands throughout the Great Plains but now exist in a mosaic of patches in agricultural fields, roadsides, and remaining prairies fragments (Brower and Pyle 2004; Oberhauser et al. 2008). Recently, milkweed growing in agricultural fields has been reduced through the increased use of herbicide tolerant corn and soybeans, which has decreased the milkweed naturally occurring within these fields (Oberhauser et al. 2001, 2008; Pleasants and Oberhauser 2013; Jepsen et al. 2015; Stenoien et al. 2018). Roadside milkweed has also been reduced through frequent mowing and herbicide use.

The monarch population decline and habitat loss have spurred efforts to conserve monarchs at the local, state, national and international levels (Ward 2014; Shahani et al. 2015; Nguyen 2017; Panella 2017). As part of these initiatives numerous citizen scientist based programs have emerged, targeting topics varying from surveying and tracking migration (e.g. Journey North, the Western Monarch Thanksgiving Count), larval health (e.g. Monarch Larval Monitoring Project, Monarch Health), to increasing monarch habitat (e.g. MonarchWatch; Jepsen et al. 2015).

A number of programs encourage landowners residing in the migratory pathway to plant milkweed gardens to support conservation (i.e. MonarchWatch's "Monarch Waystations" Taylor 2017). The purpose of these gardens is to increase monarch habitat (Oberhauser et al. 2008) and to increase connectivity among milkweed patches (Zalucki and Lammers 2010; Zalucki et al. 2016). These citizen scientist programs have attracted thousands of participants (Nail et al. 2015; Taylor 2017) and influential groups such as the US Department of Agriculture list gardens as a way to help monarchs locally (USDA 2017).

While citizen scientist programs are widely advertised, promoted, and funded, little is known about what contribution to conservation these efforts actually make. Though they are intended to provide milkweed for larvae and, sometimes, nectar plants for adults, gardens differ from native habitats in key ways. Gardens are typically smaller, fragmented, and often planted with commercially sourced milkweed, compared to conservation areas that are larger, continuous, and have naturally occurring milkweed species present. The effects of such differences on monarch recruitment and larval survival is not well understood but key to determining the value of milkweed gardens. Results of prior studies using experimental milkweed plantings intended to mimic conditions found in gardens and natural sites suggest that while gardens are attractive to ovipositing adults (Cutting and Tallamy 2015; Stenoien et al. 2015), a better understanding of the survival of eggs and larvae in gardens relative to natural areas is needed (Majewska et al. 2018). The efficacy of milkweed gardens as a conservation tactic is important both because of the investment being committed to promoting gardens, and the potential risk of attracting monarchs to oviposit in habitats where larval survival is unlikely.

We estimated survival of monarch caterpillars in milkweed gardens, with a special emphasis on evaluating the risk of parasitism by the tachinid fly Lespesia archippivora. Adult females lay eggs on monarch larvae. Upon hatching the maggots bore into the larva, ultimately causing mortality (Etchegaray and Nishida 1975). We also evaluated the potential for parasitism by the obligate protozoan (Ophryocystis elektroscirrha) that can leave monarchs with deformed wings and increased mortality (McLaughlin and Myers 1970; Altizer et al. 2000). Parasitism rates by L. archippivora and $O$. elektroscirrha can be influenced by habitat (Zalucki 1981; Prysby 2004; Tooker et al. 2006; Oberhauser et al. 2007). The more parasitized adults that visit the same milkweed the higher the spore load becomes (Bartel et al. 2011). Thus, the potential exists for parasitism rates in small gardens to become elevated.

Our approach was to compare monarch demography and parasitism rates in existing gardens to native prairie fragments and prairie restorations. For most species of conservation concern in the Great Plains, conservation efforts have focused on protecting, managing, and restoring grasslands - a strategy we will hereafter refer to as traditional conservation. Understanding the effect these gardens have on monarch recruitment and demography is vital to maximizing the conservation benefits of milkweed gardens. We hypothesized that: (1) egg numbers, (2) larval survival, and (3) parasitism rates differ between garden plantings and conservation areas. To evaluate these hypotheses, we quantified egg and larval abundance and demography at conservation areas and gardens in 2016 and 2017. We then collected and reared late instar monarch larvae to compare parasitism rates between gardens and conservation areas.

\section{Methods}

We compared monarch egg and larval density, larval survival, and larval parasitism on milkweed naturally occurring in conservation areas to milkweed planted in gardens. As the basis for comparison to gardens, we used five conservation areas within the Omaha, Nebraska metropolitan area 
(Supplemental Material Fig. 4, Table A.1). The conservation sites were all tallgrass prairies set in urban or suburban landscapes. These sites varied from 5 to 178 ha and were actively managed through prescribed burning and/or mowing (Supplemental Material Table A.1).

We found gardens by describing the goals of the project to garden clubs and horticulture societies and requesting help finding gardens that could qualify as "Monarch Waystations" (Taylor 2017). The largest citizen science initiative focused on monarchs, Monarch Watch designates gardens of any size that contain at least two species of milkweed with a total of at least ten stems of milkweed as a "Monarch Waystation" (Taylor 2017). From gardeners who responded and who were willing to accept regular visits to their property, we chose fifteen sites based on accessibility of the gardens and proximity to our lab facilities to maximize the number of sites we could monitor. We eliminated two of the fifteen gardens a month after the start of the 2016 field season because the gardeners had removed all milkweed. The remaining 13 gardens within residential areas of the Omaha metropolitan area consisted of five private gardens and eight public gardens (Supplemental Material, Table A.2).

\section{Field observations}

Monarch larvae hatch from eggs approximately four days of being laid and pass through five developmental instars over a period of 9-14 days (Oberhauser 2004) though these rates vary depending on temperature and other environmental factors (Rawlins and Lederhouse 1981; Zalucki 1982). They then pupate and emerge from chrysalises as butterflies within 14 days. Instars are distinguishable from one another based on easily visible characteristics (Oberhauser and Kuda 1997; Urquhart 1998; Geest 2017).

We visited each field site every 4 days visually checking each milkweed stem for larvae and eggs and recording counts for each instar (Oberhauser et al. 2009; CEC 2017; Geest 2017). Using these data, we constructed survival curves to quantify differences in population demography between conservation sites and gardens. We collected all 4th and 5th instars and reared them to adulthood in the lab to estimate rates of parasitism (see below). We recorded the presence and instar of any depredated or deceased larvae that we found.

Because conservation areas are large relative to gardens, two patches of milkweed were located within each study site. These patches were chosen based on ease of access and the number of milkweed stems present. By choosing large patches of milkweed, we could efficiently maximize the number of stems checked at every visit. The area and number of milkweed stems varied among sites (Geest 2017) we recorded patch area $\left(\mathrm{m}^{2}\right)$ and number of milkweed stems to include in analyses (see below). Within each of these patches within the conservation areas we examined every milkweed stem at every visit. In gardens, due to the smaller number of plants, we examined every stem of milkweed in the entire garden during each visit. Due to the larger number of plants in prairies, we devoted more time and effort searching conservation areas relative to garden sites. We searched garden and prairie field sites during the period when adult monarchs were present in the area: May 21 through September 3 in 2016 and May 8 through August 25 in 2017.

\section{Larvae rearing}

All 4th and 5th instar larvae found were collected and reared in the lab to measure rates of parasitism. L. archippivora is unlikely to successfully parasitize larvae at instar five and collecting at instar four allows the maximum amount of time for the larvae to be parasitized (Etchegaray and Nishida 1975; Borkin 1982). Larvae were collected with the leaf they were found on to reduce overall larva stress and avoid the defensive act of immobilizing, falling into the leaf litter below, and escaping (Grace 1997; Mueller and Baum 2014).

We reared larvae until adulthood following protocols developed by Altizer and Oberhauser (1999). Each larva was housed in a ca $1 \mathrm{~L}$ (32 oz.) plastic container with a cheesecloth lid and a wooden skewer to pupate on. The larvae were kept on a natural light and dark cycle, and checked daily for signs of parasitism. We provided fresh milkweed leaves to larvae daily. Every leaf was surface sanitized by rinsing in $10 \%$ bleach solution, rinsed in deionized water, and dried before being given to the larvae to prevent accidental spore and mold introduction (Altizer and Oberhauser 1999; Mueller and Baum 2014).

If parasitoids emerged during rearing, they were collected and identified to species (Wood 1987; O'Hara 2013). If a caterpillar died, we waited $24 \mathrm{~h}$ for maggots to emerge: if a larva died and no parasitoids emerged we dissected to determine if parasitoids were present (Oberhauser et al. 2007). If fly larvae were detected upon dissection, the maggots were collected and allowed to pupate normally. If a caterpillar larva stopped feeding and died with no noticeable cause it was classified as "Failure-to-thrive" syndrome (Oberhauser et al. 2007).

Butterflies that successfully eclosed were tested for $O$. elektroscirrha spores once their wings fully dried, following the methods outlined in Altizer et al. (2000). In brief, monarchs were grasped at the base of their wings exposing their abdomens and a clear, adhesive mailing seal (Avery ${ }^{\circledR}$ $5248^{\mathrm{TM}}$ ) was then placed along the abdomen, removed, and placed on a microscope slide. Slides were viewed under a microscope at $\times 400$ magnification and a parasite load rating was given based on total spores counted. For example, a spore count of $0=$ a score of $0,1=1,2-20=2,21-100=3$, $101-1000=4,1001+$ spores $=$ a score of 5 (Altizer et al. 
2000). All adults were subsequently released at the original collection site.

\section{Measuring milkweed density}

We measured two components of milkweed density in conservation areas that occur at two different spatial scales: patch density and site density. First, we quantified milkweed density in the two patches surveyed at each site by measuring the area of each milkweed patch and counting the total stems of milkweed at each visit. Second, we quantified milkweed density across the entire conservation site for each prairie during the peak milkweed blooming period in late June. Site-level measurements were based on counts of milkweed stems in $1 \mathrm{~m}^{2}$ quadrats placed every $10 \mathrm{~m}$ along $100 \mathrm{~m}$ transects. Ten transects were randomly placed in each prairie (Geest 2017).

In gardens, we measured the total area of the gardens at the beginning of the study and then counted the stems of milkweed at every visit to quantify the number of stems available to monarchs at each site.

\section{Analysis}

We did not detect every egg or larva present within each site at every visit. In order to estimate survival curves, we used a back counting approach to correct for missed observations (De Anda and Oberhauser 2015). The average time it takes for a larva to move from one instar to the next is less than 4 days under typical field conditions. Based on this timing we made the assumption that eggs should be first instars by the next visit, first instars should be second instar, etc. If all eggs and larvae were detected on visit one, then the numbers of the subsequent stages found on visit two should be less than or equal to those on the first visit. If we found the number of larvae in an instar had increased relative to the previous stage and visit, we assumed a missed detection had occurred in the prior visit and corrected for the missed detection by adding an individual to the previous count. With the corrections, the data represent a minimum level of mortality between stages. We tested whether there were differences in the adjusted number of eggs between years and between habitat types (residential gardens versus conservation sites) by using linear mixed models and least squared means comparisons using the lme4, lmtest, lmerTest packages from $\mathrm{R}$ (R Core Team 2016; Bates et al. 2015; Kuznetsova et al. 2017; Zeileis and Hothorn 2002).

\section{Survival and parasitism analysis}

We compared survival from egg to adult in conservation areas and in residential gardens using the survival package in
$\mathrm{R}$ to generate Kaplan-Meier survival curves and compared survival between the two types of sites using a log rank analysis (R Core Team 2016; Therneau 2016). Effects of site type on parasitism rates were analyzed using a Chi squared test to compare proportion of parasitism rates between residential gardens and conservation areas for tachinid parasitoids and O. elektroscirrha. Ratios of male to female adults produced by garden and conservation sites were compared using Chi square tests. Divergence of the sex ratios from a 50:50 ratio was tested using binomial tests.

\section{Effects of habitat variables on monarch demography and parasitism}

We evaluated the influence of habitat variables on difference in number of eggs and incidence of parasitism among garden sites and among conservation sites using generalized linear mixed models (GLMM) using the lme4 package in R (Bates et al. 2015; R Core Team 2016). We used a Poisson distribution with site and visit number included as random effects. Prior to using the patch-level density in our models we confirmed that the measurements between patch-level and site level densities were not correlated (R Core Team 2016; Geest 2017). In prairies patch-level density was measured at each visit and the average measurement from the two closest visit dates to the transect survey used for the site-level density was used. For milkweed density in gardens, we averaged the total stems from each visit and used a mean milkweed density. We removed two gardens from the analysis in 2016 and one in 2017 due to low number of eggs recorded and because no larvae were collected from those sites. For each individual site, we also removed all visit data from each site until the first egg was counted, because it was unknown why monarchs were not at the site before eggs were detected. To interpret the direction and significance of relationships we reported the beta estimate of each GLMM.

\section{Results}

\section{Monarch recruitment}

The number of stems inspected varied among sites and within each site across the season. At conservation areas we surveyed an average of $117.4 \pm 11.8$ milkweed stems per visit and at gardens we inspected an average of $100.5 \pm 41.2$ stems per visit (Table 1). The number of monarch eggs varied among sites (Table 1) but did not differ significantly between residential and conservation sites. In 2016 conservation averaged $14.0 \pm 7.4$ eggs (95\% CI -1.8 to 29.8 ) and garden sites averaged $26.5 \pm 4.6$ eggs (95\% CI 16.8-36.3; $d f=16, \mathrm{t}=1.43, \mathrm{p}=0.172)$. In 2017 conservation averaged $38.8 \pm 30.2$ eggs (95\% CI -25.3 to 1002.9$)$ and garden sites 
Table 1 Average stems of milkweed (Asclepias spp.) stems present and inspected at each visit across both 2016 and 2017 for all sites

\begin{tabular}{|c|c|c|c|c|c|}
\hline Site name & Average stems $\pm \mathrm{SE}$ & Sum eggs & $\begin{array}{l}\text { Sum larvae } \\
\text { collected }\end{array}$ & Eggs/stem & $\begin{array}{l}\text { Larvae } \\
\text { collected/ } \\
\text { stem }\end{array}$ \\
\hline \multicolumn{6}{|l|}{ Conservation areas } \\
\hline Allwine Prairie & $154.9 \pm 14.6$ & 50 & 54 & 0.3 & 0.3 \\
\hline Audubon Society of Omaha Prairie Preserve & $87.1 \pm 6.3$ & 49 & 3 & 0.6 & $<0.1$ \\
\hline Bauermeister Prairie & $118.1 \pm 6.9$ & 45 & 5 & 0.4 & $<0.1$ \\
\hline Bluestem Prairie Preserve/Stolley Prairie & $128.1 \pm 13.2$ & 23 & 1 & 0.2 & $<0.1$ \\
\hline Schneekloth South Prairie & $98.5 \pm 7.2$ & 12 & 12 & 0.1 & $\begin{array}{l}0.1 \\
0.1 \pm 0.1\end{array}$ \\
\hline \multicolumn{6}{|l|}{ Residential gardens } \\
\hline 105th street & $162.8 \pm 8.6$ & 127 & 25 & 0.8 & 0.2 \\
\hline 46th street & $66.1 \pm 5.0$ & 25 & 11 & 0.4 & 0.2 \\
\hline 80th street & $63.4 \pm 2.9$ & 43 & 27 & 0.7 & 0.4 \\
\hline Bellevue Public Library & $36.6 \pm 1.2$ & 57 & 15 & 1.6 & 0.4 \\
\hline Gemini Park & $91.6 \pm 6.1$ & 189 & 47 & 2.1 & 0.5 \\
\hline Heron Haven Sanctuary & $30.4 \pm 1.9$ & 5 & 2 & 0.2 & 0.1 \\
\hline Joslyn Art Museum's Children's Discovery Garden & $135.7 \pm 7.1$ & 90 & 27 & 0.7 & 0.2 \\
\hline Logan Middle School & $44.4 \pm 2.3$ & 33 & 14 & 0.7 & 0.3 \\
\hline New Life Baptist Church & $12.4 \pm 0.9$ & 0 & 0 & 0.0 & 0.0 \\
\hline Northern Hills Drive & $571.8 \pm 37.1$ & 89 & 122 & 0.2 & 0.2 \\
\hline St. Thomas More Catholic School & $17.3 \pm 1.4$ & 15 & 4 & 0.8 & 0.2 \\
\hline Sump Memorial Library & $31.3 \pm 2.6$ & 17 & 0 & 0.5 & 0.0 \\
\hline Waldo Circle & $42.3 \pm 1.9$ & 33 & 23 & 0.8 & 0.5 \\
\hline
\end{tabular}

The total number of monarch eggs counted and total number of monarch larvae collected at each site are presented and then standardized by the average number of stems inspected. Number of stems represents the Mean \pm SE across all visits

averaged $68.1 \pm 18.8$ eggs (95\% CI 28.3-107.8; $d f=16$, $\mathrm{t}=0.823, \mathrm{p}=0.423)$. The number of eggs found across all sites was higher in 2017 than in 2016 [2016 $=23.1 \pm 11.5$ eggs (95\% CI -0.5 to 45.7$)], 2017=59.9 \pm 11.5$ eggs $(95 \%$ CI $37.3-82.5 ; d f=17, \mathrm{t}=-2.63, \mathrm{p}=0.017$ ).

In 2016, we collected 27 fourth and fifth instar monarch larvae at conservation areas and 103 at gardens and reared them in the lab (Table 2). In 2017, we collected 48 monarch larvae at conservation areas and 214 larvae at gardens. The number of fourth and fifth instar larvae found varied among sites with an average of $15.0 \pm 9.9$ caterpillars per conservation site (95\% CI -12.6 to 42.6$)$ and $24.4 \pm 9.0$ caterpillars per garden (95\% CI 4.9-43.9; Table 1). Among the larvae reared in the lab, parasitism by tachinids accounted for 21 of 27 mortality events for larvae from conservation sites and 98 of 117 mortality events for larvae from gardens (Table 2). The ratios of males and females of monarchs that emerged as butterflies were similar for conservation areas
Table 2 Fates of 4th and 5th instar monarch larvae collected and reared in the lab in 2016 and 2017 at conservation sites and gardens

\begin{tabular}{|c|c|c|c|c|c|}
\hline \multirow[t]{2}{*}{ Year } & \multirow[t]{2}{*}{ Survived } & \multicolumn{4}{|l|}{ Cause of death } \\
\hline & & $\begin{array}{l}\text { Parasitism by } \\
\text { fly }\end{array}$ & $\begin{array}{l}\text { Failure-to- } \\
\text { thrive }\end{array}$ & $\begin{array}{l}\text { Failure to } \\
\text { eclose }\end{array}$ & $\begin{array}{l}\text { Unknown } \\
\text { causes }\end{array}$ \\
\hline \multicolumn{6}{|l|}{2016} \\
\hline Conservation & $20(11$ ㅇ, 9 ठึ) & 6 & & & 1 \\
\hline Gardens & $72(40$ q, 32 ふૈ) & 27 & 3 & 1 & \\
\hline \multicolumn{6}{|l|}{2017} \\
\hline Conservation & $28(16$ ๆ, 12 ठ) & 15 & 1 & & 4 \\
\hline Gardens & $128(61$ 오, 67 ふึ) & 71 & 7 & & 8 \\
\hline
\end{tabular}

Mortality during the larval or chrysalis stage included parasitism by tachinid flies, larval death attributed to "failure to thrive" syndrome (sensu Oberhauser et al. 2007), and unexplained mortality. Individuals that survived to adulthood were sexed and released 
and gardens in 2016 [ $\left.X^{2}(1, \mathrm{~N}=92)=0.002, \mathrm{p}=0.965\right]$, in $2017\left[X^{2}(1, \mathrm{~N}=156)=0.49, \mathrm{p}=0.483\right]$, and with the years combined $\left[X^{2}(1, N=248)=0.31, p=0.579\right.$; Table 2]. Sex ratios did not deviate from 50:50 for any group (binomial test, all $\mathrm{p}>0.20$ ).

The timing of occurrence of monarch eggs did not differ between the types of sites in either year (Geest 2017). Late instar monarch larvae were found and collected in gardens before conservation areas in both years (Fig. 1). In 2016 in garden sites the first monarch larva collected was 49 days earlier than in conservation areas. Similar to 2016, in 2017 the first larva collected from residential gardens was 20 days earlier than the first larva collected from conservation areas. Peak collection periods were similar for conservation areas and gardens in 2016 but started earlier for gardens in 2017. In 2016, the peak collection period was from August 19 until September 3 where $85.2 \%$ of conservation larvae were
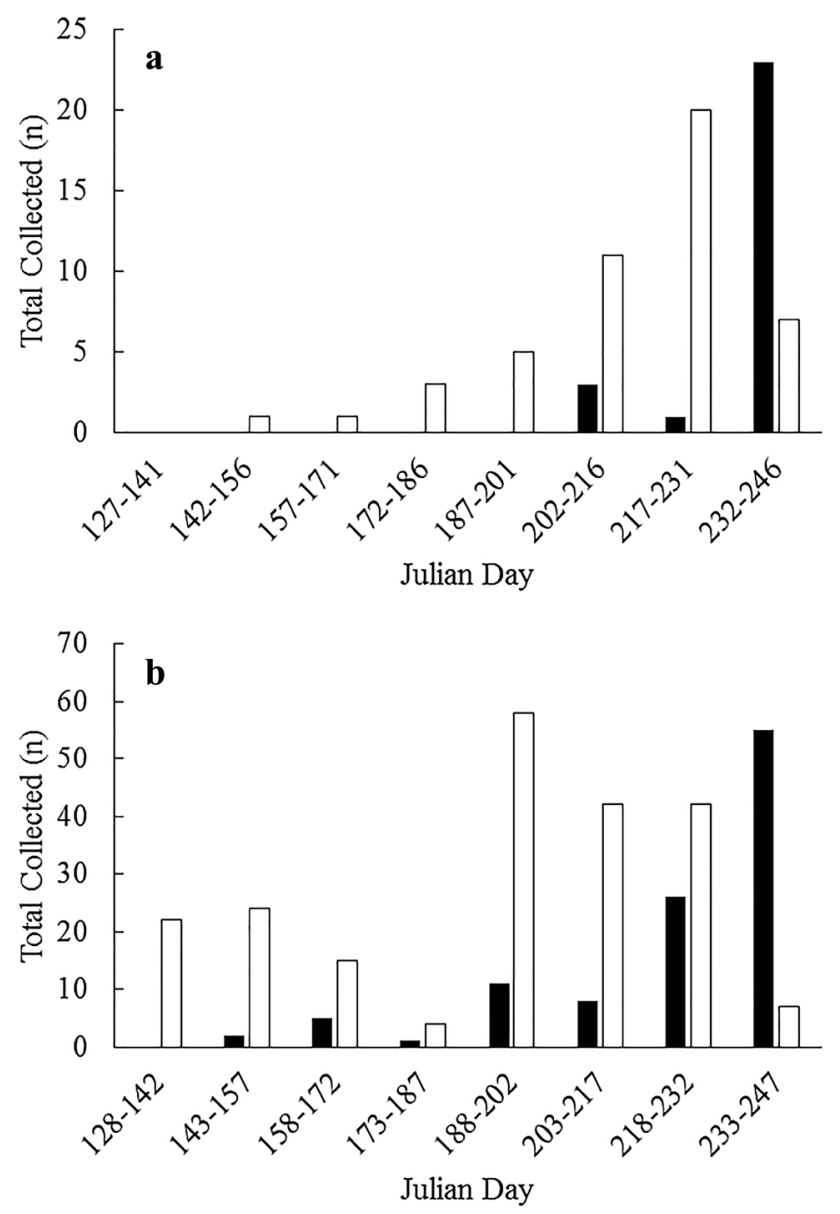

Fig. 1 Timing of collection of monarch larvae (Danaus plexippus) from conservation areas (a) and residential gardens (b) in 2016 and 2017. Solid bars represent 2-week periods from May until September of 2016. Hollow bars are two-week periods from March until August of 2017. The $y$-axis is number of monarch larvae (4th and 5th instars) collected and the $x$-axis is the Julian day of collection. Note the difference in scale of $y$-axis collected and $53.4 \%$ of garden larvae were collected (Fig. 1). In 2017, the peak collection period for conservation areas was from August 5 until Aug 19 where $41.6 \%$ of larvae were collected, while for gardens it was from July 7 until August 20 where $66.4 \%$ of larvae were collected (Fig. 1).

\section{Monarch survival}

In conservation areas survival from egg to adult was higher in $2016(0.29 \pm 0.05(\mathrm{SE}))$ than in $2017(0.14 \pm 0.03 ; \mathrm{Log}$ rank, $X^{2}=6.2, d f=1, \mathrm{p}=0.01$; Fig. $2 \mathrm{a}$ ). In gardens survival from egg to adult was also higher in $2016(0.21 \pm 0.02)$ relative to $2017\left(0.15 \pm 0.01 ; \log\right.$ rank, $X^{2}=4.0, d f=1$, $p=0.05$, Fig. $2 b$ ). Survival did not differ between conservation and garden sites in 2016 (Log rank, $X^{2}=1.5$, $d f=1, \mathrm{p}=0.22$; Fig. $2 \mathrm{c})$ or $2017\left(\log\right.$ rank, $X^{2}=1.1, d f=1$, $\mathrm{p}=0.30$; Fig. $2 \mathrm{~d})$. Across the 2 years, survival in conservation areas $(0.18 \pm 0.02)$ and gardens $(0.16 \pm 0.01)$ was similar (Log-rank test, $X^{2}=0, d f=1, \mathrm{p}=0.87$ ).

\section{Lespesia archippivora parasitism}

Parasitism rates by L. archippivora were similar between conservation areas and gardens in 2016 (conservation areas: $22.2 \%$ and gardens: $26.2 \%, X^{2}(1, \mathrm{~N}=130)=0.105, \mathrm{p}>0.10$; Table 2), in 2017 (conservation areas: $31.3 \%$ and gardens: $33.2 \%, X^{2}(1, \mathrm{~N}=262)=0.034, \mathrm{p}>0.10$; Table 2$)$, and with the 2 years combined (conservation areas: $27.6 \%$ and gardens: $30.9 \%, X^{2}(1, \mathrm{~N}=392)=0.244, \mathrm{p}>0.10$; Table 2). There was no difference in parasitism rates between 2016 and 2017 in either conservation areas $\left(X^{2}(1, N=75)=0.699\right.$, $\mathrm{p}>0.10)$ or gardens $\left(X^{2}(1, \mathrm{~N}=317)=1.579, \mathrm{p}>0.10\right)$.

Peak times of parasitism varied across both field seasons in both conservation areas and gardens but followed a general trend of high parasitism early in the season, followed by a period of no parasitism, with another wave of parasitism late in the field season (Fig. 3). In both years the period of no parasitism in conservation areas or in gardens occurred from June 14 to July 16.

\section{Ophryocystis elektroscirrha parasitism}

In 2016, only 4 monarchs out of 92 (4.3\%) adults tested were infected with $O$. elektroscirrha. Three of these butterflies came from a single garden and the remaining one was collected from a conservation area. The three butterflies from a single garden were heavily infected with a spore load of 4 while the conservation butterfly had a spore load of 3 . In 2017, only 1 adult out of $156(0.6 \%)$ was infected with spores with the single butterfly being heavily infected with a spore load of 4 . This sole spore infected butterfly came from a garden. In both years, the butterflies with $O$. elektroscirrha occurred at the end of the field season in the migratory 

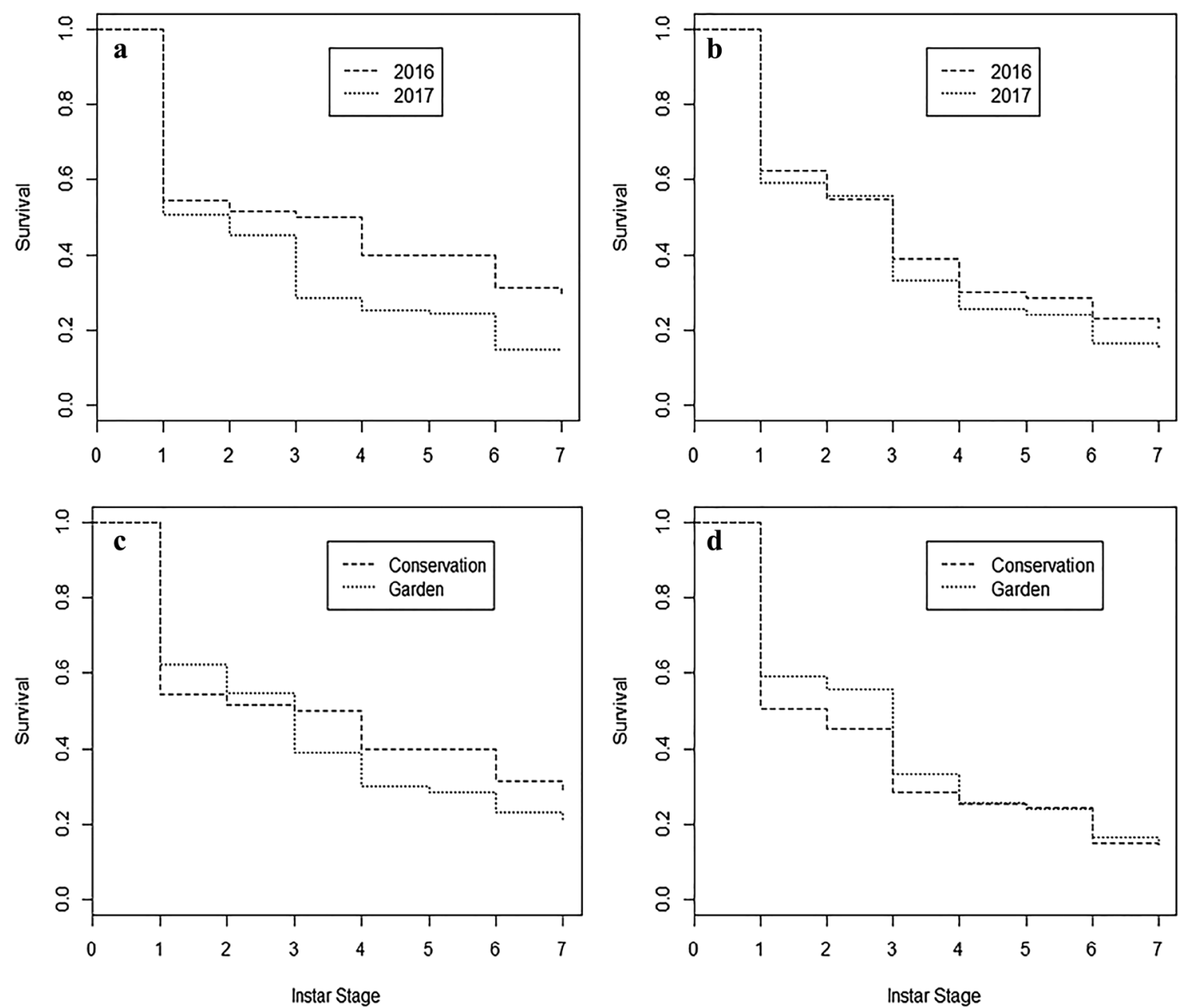

Fig. 2 Kaplan-Meier survival curves for monarch butterflies (Danaus plexippus) where the $y$-axis is the survival rate and the $x$-axis is the monarch life stage $(0=\mathrm{egg}, 1-5=$ instars, $6=$ chrysalis, $7=$ adult $)$. In both conservation areas (a) and gardens (b) survival from egg to adult

is higher in 2016 than in 2017 ( $\log$ rank, $\left.X^{2}=6.2, d f=1, \mathrm{p}=0.01\right)$. Survival did not differ between conservation and garden sites in 2016 (c) $\log$ rank, $\left.X^{2}=1.5, d f=1, \mathrm{p}=0.22\right)$ or $2017\left(\mathbf{d} ; \log\right.$ rank, $X^{2}=$ $1.1, d f=1, \mathrm{p}=0.30$ )

generation. There was no significant difference in parasitism by $O$. elektroscirrha between the two habitat types (Fishers Exact Test, $\mathrm{p}=1.00$ ).

\section{Milkweed species and density}

Site level and patch level milkweed density in conservation areas were not correlated in either year (2016: $r=0.43$, $\mathrm{p}=0.47,2017: r=0.32, \mathrm{p}=0.61$; Supplemental Material Table A.3). Conservation areas had between 1 and 3 Asclepias species present with $A$. syriaca found at every site both years (Geest 2017). The mean number of Asclepias species per conservation area in 2016 and 2017 was $1.2 \pm 0.03 \mathrm{SE}$ and $1.7 \pm 0.08 \mathrm{SE}$, respectively. Every garden site had at least one species of milkweed with one garden in 2016 having nine species and one garden in 2017 having eighteen species (Supplemental Material Table A.2). The mean number of milkweed stems per garden in 2016 was $68.9 \pm 25.2 \mathrm{SE}$, however there was high variability from garden to garden with the minimum number of stems being 9.63 and the maximum 353.81. In 2017, the mean number of milkweed stems increased to $134.74 \pm 11.07$ with the variability in gardens increasing as well with a minimum number of stems being 14.46 and the maximum 774.83 (Supplemental Material Table A.2).

Milkweed density at conservation areas varied among sites in 2016 and 2017 but this variation did not explain variation in monarch egg numbers or L. archippivora parasitism (all $\mathrm{p}$-values $>0.05$ ). Likewise, milkweed density did not influence monarch egg numbers at garden sites (all p-values $>0.05$ ). However, in 2016 gardens with lower densities of milkweed had higher incidence of L. archippivora parasitism (GLMM, $\mathrm{z}=-2.93, \mathrm{p}=0.003, \mathrm{SE}=1.24, \beta=-3.63)$. The size of sites did not explain variation among sites in the number of 

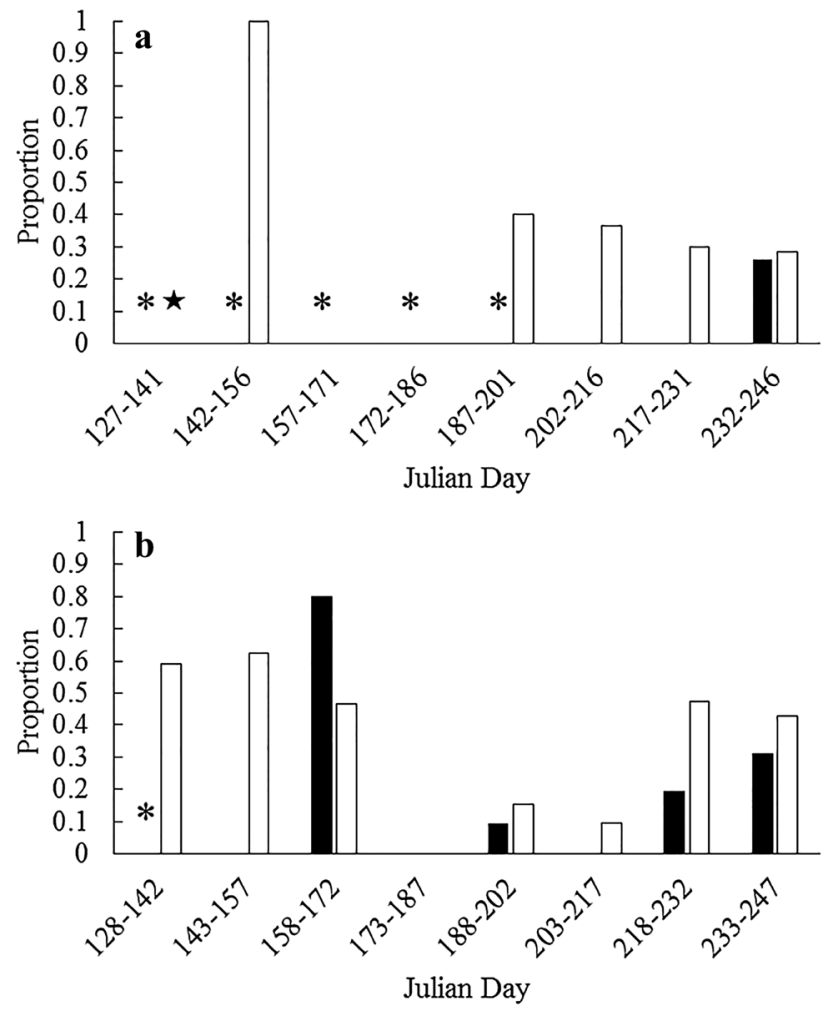

Fig. 3 Proportion of monarch larvae (Danaus plexippus) parasitized by Lespesia archippivora in conservation areas (a) and residential gardens (b) in 2016 and 2017. Solid bars are 2 week periods from May until September of 2016. Hollow bars are 2 week periods from March until September of 2017. The $y$-axis is proportion of monarch larvae parasitized and the $x$-axis is the Julian day of collection for the monarch larva. An asterisk denotes period of time when no monarch larvae were collected in 2016. A star denotes period of time when no monarch larvae were collected in 2017

monarch eggs or incidence of parasitism in either conservation areas or milkweed gardens in either year (all p-values $>0.05$; Supplementary material Table A.4).

Twelve different species of milkweed were recorded in 2016 with $A$. syriaca being the predominant milkweed species at every site except at two gardens where $A$. incarnata was the only species planted. In 2017, one garden planted an additional 6 species of milkweed bringing the total number of different milkweed species recorded to 18. A. syriaca remained the predominant species found in every garden except the two that solely had A. incarnata. In 2016 and 2017 the majority of collected monarchs came from A. syriaca (2016: $84.6 \%$ and 2017: 85.5\%). Across both years monarchs were found to use $11 \%$ of available $A$. syriaca stems.

\section{Discussion}

Significant effort and resources are being directed towards establishing milkweed gardens as part of the conservation strategy directed at monarch butterflies (Panella 2017; Pleasants et al. 2017). While these gardens attract adult butterflies, it is important to understand if reproduction in gardens is successful, relative to traditional conservation areas. If monarch eggs laid in gardens do not survive through to the adult stage investment in gardens may not be a good use of scarce conservation resources. Garden sites could be population sinks as has been suggested for some butterfly species (e.g. Levy and Connor 2004) or even act as ecological traps if adults are attracted away from sites where successful reproduction is more likely.

Our approach was to compare reproduction on milkweed found in existing gardens to that found in conservation areas. The previous studies that have most directly addressed the potential contribution of gardens to monarch conservation have used experimentally planted milkweed to mimic conditions in gardens and natural areas (Cutting and Tallamy 2015; Majewska et al. 2018). The advantage of this experimental approach is that it controls for other differences among sites such as milkweed variety, density and other management activities. In contrast, our approach of using existing gardens and conservation sites deliberately introduces variation in site characteristics and management activities known to be important determinants of butterfly reproductive success including plant choice, chemical use, and weed control (Levy and Connor 2004; Muratet and Fontaine 2014; Nail et al. 2015; Stenoien et al. 2015). While this observational approach is not a substitute for carefully controlled experimental studies, it provides an important complement to those results that encompasses the conditions butterflies experience in the field.

\section{Monarch recruitment}

To contribute to conservation, gardens must first attract adults to lay eggs. Female monarchs are selective about the milkweed stems they choose to oviposit on and do not use all of the host plants that are available to them (Borkin 1982; Stenoien et al. 2015). We used total number of eggs within a study site as one measure of monarch recruitment. Overall, we found more eggs in gardens than in conservation areas both years, in spite of the fact that conservation sites were larger and we spent more time searching those areas. However, the number of eggs found varied widely among both conservation and garden sites, producing broad and overlapping confidence intervals and the 
differences were not significant. The lack of a consistent difference in eggs between conservation and garden sites suggests that gardens have the potential to recruit as many egg laying monarchs as traditional conservation sites. This conclusion is consistent with results from previous studies that found higher egg densities in gardens (Stenoien et al. 2015) and on milkweed planted in a residential setting compared to natural areas (Cutting and Tallamy 2015). Equally important, however, is the variability in egg density itself. The high variability we observed among both conservation areas and gardens emphasizes that other characteristics of sites produce large differences in the value of sites for monarchs that overwhelm any effects of conservation or garden status.

Monarch egg laying activity at all sites built up over the season, peaking with the final migratory generation in late summer. In 2017, monarchs arrived early relative to most years (Howard and Davis 2015), with adults being observed in late March and eggs first being detected in early May. In comparison, in 2016 the first sightings of adults were in mid to late May while eggs were first observed during the final week of May. By the end of May in 2016, 22 eggs had been detected across all study sites. In 2017, 257 eggs had been observed across all study sites by the end of May. This difference between years was not limited to our study area. In 2017, multiple observers noted monarchs arrived in Nebraska in mid to late March, representing the earliest recorded arrival of adult monarchs since at least 2000 (Graham 2017; Journey North 2017). The generation that arrived in Nebraska in early 2017 was the overwintering generation from Mexico which normally does not travel further north than southern Texas (Oberhauser et al. 2001; Graham 2017). It has been suggested that strong winds are the reason the monarchs traveled so far North so quickly in 2017 (Graham 2017). In contrast, in 2016 the initial generation that arrived was comprised of the offspring of the overwintering generation, also called the first adult generation. While this is the generation expected to reach Nebraska, a late February 2016 ice storm in the monarch's over-wintering region of Michoacán, Mexico killed over a million monarchs preparing to migrate north into Texas (Maeckle 2016) and may have delayed the arrival of monarchs to Nebraska and contributed to the small initial numbers of arriving monarchs in 2016.

\section{Monarch survival}

Our analysis of monarch survival found no difference between gardens with planted milkweed and conservation areas in either 2016 or 2017. When we combined data from the 2 years, we estimated survival for monarchs in garden areas was $16.2 \%$ and in conservation areas $18.2 \%$ though the differences were not significant. Survival was higher in 2016 than in 2017 in both conservation areas and residential gardens. This is consistent with Cutting and Tallamy's (2015) experimental study that found no consistent difference in overall survival between monarchs using milkweed planted in residential and natural sites. Likewise, in their analysis of the long-term citizen-science based Monarch Larva Monitoring Project data, Nail et al. (2015) included site type in their analysis but a site's status as a garden did not emerge as one of the top models explaining survival. While this pattern starts to suggest that gardens can provide suitable habitat for monarch reproduction, Majewska et al. (2018) sounded a cautionary note based on their finding that larval survival was lower in their experimental garden sites relative to more natural sites outside the gardens.

The period of greatest mortality is from egg to 1 st instar in both habitats in both years, as has been found in other studies of monarchs (e.g. Borkin 1982; Zalucki et al. 2001b; Prysby 2004; Oberhauser et al. 2007). Eggs and early instars may be especially vulnerable to predation due to a lack of protection from toxins that later instars have developed from consuming milkweed (Zalucki 1981) and can also suffer mortality from latex drowning (Zalucki and Brower 1992; Zalucki et al. 2001a). We produced survival curves that include transition from larval to adult stages. This portion of monarch survival is determined by rearing 4 th and 5 th instars indoors, rather than in the field because 5th instars leave milkweed to pupate and finding cryptically colored chrysalises in the wild are extremely rare and resource intensive (Borkin 1982; Oberhauser et al. 2007; Nail et al. 2015). Indoor rearing results in protecting larvae and pupa from predation, additional parasitoids, weather, exposure to insecticides, and other sources of mortality, producing estimates of survival that are almost certainly higher than occur naturally (Oberhauser et al. 2007; Nail et al. 2015). However, including this stage in analyses of survival is important because of the high mortality associated with parasitism that is not reflected in survival curves that end at the 3rd or 4th larval instar (Nail et al. 2015).

Our overall estimates of survival across life stages varied from 14.4 to $31.4 \%$, placing our estimates at the high end compared to previous studies that reported survival rates between 2 and 24\% (Borkin 1982; Oberhasuer et al. 2001; Prysby 2004; Cutting and Tallamy 2015; Nail et al. 2015). The substantial variation reported in survival is not surprising given that these studies were conducted across a species range, in varying habitats, and in different years (Zalucki and Kitching 1982b). As in our study, year to year variation has been found to be substantial within a site and estimates of survival benefit from long-term studies that quantify year-toyear variability (Nail et al. 2015). In addition, methodological differences may contribute to the variation in survival reported by different studies. For example, the time between checks of milkweed plants and larvae varied among studies from a day (Cohen and Brower 1982; Prysby 2004; De Anda 
and Oberhauser 2015), to 3 or 4 days (Zalucki and Kitching $1982 \mathrm{~b}$, this study), to a week or more (Borkin 1982; Oberhauser et al. 2001; Nail et al. 2015; Majewska et al. 2018). More frequent checks should result in detecting a greater proportion of eggs laid and this produce lower estimates of survival relative to studies where plants are checked less frequently and some eggs are eaten before they are detected. Likewise, to account for imperfect detectability among the early instars we chose to correct data to account for missed detections (De Anda and Oberhauser 2015) and use instarbased survival curves, while other monarch larval survival studies bypass the issue of imperfect detectability of eggs and larvae by using the ratio of the number of eggs to instar five larvae to (Calvert 2004; Nail et al. 2015; Majewska et al. 2018), while still others limit their survival estimates to the first 2 or 3 instars due to concerns about detectability of older larvae (Cutting and Tallamy 2015; De Anda and Oberhauser 2015). These and other methodological differences highlight the importance of future studies that quantify the probability of detecting eggs and larvae and what factors drive detectability using double observer or other methods (Elphick 2008).

\section{Parasitism}

Estimates of survival from egg to late instar larvae will miss much of the mortality caused by tachinid fly parasitism that can be a major source of mortality in the pupal stage (Nail et al. 2015). Because so few larvae reach this stage, variation in parasitism between gardens and natural areas could greatly influence the number of adults produced. Parasitism rates at sites used in this study ranged from 0 to $100 \%$ parasitism of collected larvae. This level of parasitism by tachinids is not atypical (Zalucki 1981), and parasitism has been found to be widely variable year-to-year and patch-topatch (Oberhauser et al. 2007). While parasitism rates were variable, variation among sites in our study was not related to their status as gardens or natural areas. While a higher proportion of larvae from gardens were parasitized, the differences were not significant. L. archippivora is considered a generalist (Etchegaray and Nishida 1975; Prysby 2004) however some studies have suggested it shows a preference for monarch larvae and other recorded host species may be due to spill-over parasitism (Janzen and Hallwach 2009; Oberhauser 2012). All collected tachinid flies were identified as L. archippivora which is not unusual since L. archippivora is the most frequent tachinid parasitoid of monarchs (Schaffner and Griswold 1938; Oberhauser et al. 2017a).

We found one peak time period for L. archippivora in conservation areas and two peak time periods for parasitoids in residential gardens. This result might suggest that L. archippivora is bivoltine with a gap between generations occurring from mid-June to mid-July which is consistent with the historical record of L. archippivora having 2 or 3 generations (Schaffner and Griswold 1938). The variability observed could be caused by collecting the parasitoids that emerged for identification instead of releasing them at their original field site. In that case, parasitism would be expected to decrease between the two field seasons in 2016 and 2017. We found the opposite pattern, with individual sites parasitism increasing from 2016 to 2017. This is consistent with findings of Oberhauser et al. (2007) who reported that less parasitism occurred in earlier sampling years despite the parasitoids being collected every year. While parasitism from the spore parasite, O. elektroscirrha, has been to found to be increasing, no similar trends have been found in tachinid parasitism (Nail et al. 2015; Satterfield et al. 2015).

In contrast to the significant rates of parasitism by $L$. archippivora, we found O. elektroscirrha on only $2 \%$ of reared monarchs which is lower than the reported average of $8 \%$ infection rate for the eastern population (Altizer et al. 2000). Any monarch larvae parasitized by L. archippivora did not survive to be tested for O. elektroscirrha, so O. elektroscirrha spore infection rates may be higher. Not surprisingly given the small number of infections, we found no difference between garden and conservation sites. In 2016, three of the four infected $O$. elektroscirrha butterflies came from the same garden. Repeated visits from infected adults increase the number of spores that are distributed across the leaves and egg cases (Bartel et al. 2011). This suggests, that only a few infected adults are needed to cause heavy spore loads in offspring.

\section{Effects of milkweed density}

One of the significant observations from our study is the large amount of variation among gardens and among prairie sites. This variability suggests that any differences that might exist between gardens and conservation areas is likely overshadowed by differences in quality among sites within each category. While the present study was not designed to determine why sites varied, we did ask how the density of milkweed might influence monarch survival or parasitism among conservation areas and residential gardens to begin to ask what makes a good prairie and a good garden for monarchs.

Milkweed density varied between sites and is known to influence monarch ovipositioning choice (Zalucki and Kitching 1982a; Zalucki and Suzuki 1987; Stenoien et al. 2015). We found a slight negative correlation between higher milkweed density and a lower number of eggs in 2017 in conservation areas and a slight positive correlation; however, neither was significant. Zalucki (1981) and Stenoien et al. (2015) found higher counts of eggs in sites with lower milkweed density. However, these studies occurred over a longer timespan than our study. Pitman (2017) similarly found 
higher egg densities in sites with lower milkweed density. Pitman (2017) suggested that higher quality plants occurred if milkweed plant at low density experienced less competition and that quality of milkweed may explain monarch oviposit choice. Egg densities per plant vary considerable across regions and years with overall densities decreasing since 2006 (Lindsey et al. 2009; Stenoien et al. 2015). Our results reflect this variation at a smaller scale, with both egg and larval numbers per stem ranging from the low end of prior reports to average or slightly above for our most productive sites.

The characteristics of gardens and conservation sites have the potential to influence parasitism rates. We found a slightly positive correlation between $L$. archippivora parasitism and lower milkweed densities within conservation areas in 2017, but it was not significant. This may be due to milkweed patches being denser than the surrounding areas within conservation sites. In residential gardens we found a significant negative correlation in 2016 suggesting that sites with lower milkweed density had higher parasitism rates. A similar study in Australia with a different species of tachinid found the reverse and that parasitism was lower in smaller patches with lower densities of milkweed (Zalucki 1981). Most tachinid species find host larvae by sight (Prysby 2004). Milkweed within gardens was typically more exposed than milkweed within prairies. Similarly, in tallgrass prairies with high amounts of vegetation milkweed patches may be easier to locate for tachinids than isolated plants.

The most widespread and abundant milkweed species in both years was A. syriaca. Milkweed stems increased across all garden and conservation sites from 2016 to 2017 , with the increase driven by an increase in stems of $A$. syriaca. This is unsurprising since $A$. syriaca can spread not only through wind dispersed seeds but also through rhizomes (Kaul et al. 2011). A. syriaca seedlings can produce large numbers of stems in short amounts of time with a single seedling creating an additional 56 stems and 94 seedlings in 4 years (Bhowmik 1978, 1994). Monarch larvae were found on approximately $11 \%$ of the $A$. syriaca stems available to them which was the most out of all native local milkweed species (Geest 2017). This is important as studies like Stenoien at al. (2015) list the loss of $A$. syriaca as one of the driving forces of population decline in the monarch. The two most commonly used host species after $A$. syriaca were A. incarnata and $A$. verticillate (Geest 2017). All three of these species have relatively low toxicity when compared to species across North America (Malcolm 1991). However, the cardenolide concentration in the leaves and shoots of the two most used host plants $A$. syriaca and A. incarnata are relatively high compared to the two least used host plants $A$. verticillata and A. tuberosa (Malcolm 1991; Rasmann and Agrawal 2011). Monarch oviposit choice has been shown to be influenced by species toxicity with female monarchs choosing species with intermediate levels of toxicity (Oyeyele and Zalucki 1990; Zalucki et al. 1990).

\section{Conclusion}

We found similar recruitment, survival, and parasitism for monarch butterflies in conservation areas and gardens, suggesting that gardens have the potential to contribute to monarch butterfly conservation. However, two important factors emerge that emphasize the challenges of realizing the potential of milkweed gardens. First, our results document the variability in quality of among gardens. Additional information about what characteristics of gardens attract monarchs and contribute to their success is needed. Second, incorporating milkweed gardens into conservation strategies must recognize the critical role the human element will play in determining if gardens benefit. At the community level, gardens have been impacted by local laws that penalize gardeners for growing milkweed because it is classified as a weed by some states at the county level (Oberhauser et al. 2008; Shahani et al. 2015). Even more significant is gardener behavior. In order for gardens to be as effective a conservation strategy as possible, gardeners must practice best conservation methods on their land. Based on our interactions, some of the same gardeners who invested in planting milkweed were also most concerned about the appearance of their garden and were reluctant to forgo the use of pesticides and to leave milkweed into the late summer when monarch use peaked but the plants had passed their most attractive stages (Geest 2017). In addition, gardens are prone to alterations year-to-year and the impact of these changes on monarchs is not known but will need to be addressed. While the overall conclusion of our research is that there are potential benefits of using residential gardens as a conservation strategy for monarch butterflies, implementation of these programs needs to include a strong outreach and education component.

Acknowledgements Funding for this project was provided from the Office of Research and Creative Activity, the Department of Biology and the Office of Graduate Studies at University of Nebraska Omaha and the Small Grants Program of Prairie Biotic Research, Inc. Thanks to Theodore Burk for suggestions on project design and methods, as well as helpful comments on earlier drafts of this paper. This project could not have happened if it were not for the gardeners and prairie managers. Our gratitude to Jeff Dietz, Lindsay Brown, Devin Christensen, Isabella Lombardo, Elizabeth Kamtz, Caylynn Cruse, and Mia Siebrasse for all their help in the field.

Funding Funding for this work was provided by small grants to EA Geest from Prairie Biotic Research, Inc. and the University of Nebraska Omaha. Funders did not influence the design or interpretation of the project and have not reviewed or otherwise influenced this manuscript. 


\section{Compliance with ethical standards}

Conflict of interest None of the authors are aware of other potential conflicts of interest.

Research involving human participants and/or animals Insects and other invertebrates are not covered under U.S. animal care regulations and are not reviewed by the university's Institutional Animal Care and Use Committee (IACUC). Our research protocols followed standard methods for working with monarch butterflies. Human participants were not used in this study.

Open Access This article is distributed under the terms of the Creative Commons Attribution 4.0 International License (http://creativeco mmons.org/licenses/by/4.0/), which permits unrestricted use, distribution, and reproduction in any medium, provided you give appropriate credit to the original author(s) and the source, provide a link to the Creative Commons license, and indicate if changes were made.

\section{References}

Altizer SM, Oberhauser KS (1999) Effects of the protozoan parasite Ophryocystis elektroscirrha on the fitness of monarch butterflies (Danaus plexippus). J Invertebr Pathol 74:76-88

Altizer SM, Oberhauser KS, Brower LP (2000) Associations between host migration and the prevalence of a protozoan parasite in natural populations of adult monarch butterflies. Ecol Entomol 25:125-139

Bartel RA, Oberhauser KS, de Roode JC, Altizer SM (2011) Monarch butterfly migration and parasite transmission in eastern North America. Ecology 92:342-351

Bates D, Maechler M, Bolker B, Walker S (2015) Fitting linear mixedeffects models using lme4. J Stat Softw 67:1-48. https://doi. org/10.18637/jss.v067.i01

Bhowmik P (1978) Germination, growth and development of common milkweed. Can J Plant Sci 58:493-498

Bhowmik P (1994) Biology and control of common milkweed. Weed Sci Soc Am 6:227-250

Borkin SS (1982) Notes on shifting distribution patterns and survival of immature Danaus plexippus (Lepidoptera: Danaidae) on the food plant Asclepias syriaca. Great Lakes Entomol 15:199-206

Brower LP, Pyle RM (2004) The interchange of migratory monarchs between Mexico and the western United States, and the importance of floral corridors to the fall and spring migrations. In: Nabhan GP (ed) Conserving migratory pollinators and nectar corridors in western North America. The University of Arizona Press and the Arizona-Sonora Desert Museum, Tucson, pp 144-166

Calvert WH (2004) The effect of fire ants on monarchs breeding in Texas. In: Oberhauser KS, Solensky MJ (eds) The monarch butterfly: biology and conservation. Cornell University Press, Ithaca, pp 47-53

CEC (2017) Monitoring monarch butterflies and their habitats across North America: inventory and monitoring protocols and data standards for monarch conservation. Commission on Environmental Cooperation, Montreal

Cohen JA, Brower LP (1982) Oviposition and larval success of wild monarch butterflies (Lepidoptera: Danaidae) in relation to host plant size and cardenolide concentration. J Kans Entomol Soc $55: 343-348$
Cutting BT, Tallamy DW (2015) An evaluation of butterfly gardens for restoring habitat for the monarch butterfly (Lepidoptera: Danaidae). Environ Entomol 4:1328-1335

De Anda A, Oberhauser KS (2015) Invertebrate natural enemies and stage-specific mortality rates of monarch eggs and larvae. In: Oberhauser KS, Nail KR, Alitzer S (eds) Monarchs in a changing world: biology and conservation of an iconic butterfly. Cornell University Press, Ithaca, pp 60-70

Elphick CS (2008) How you count counts: the importance of methods research in applied ecology. J Appl Ecol 45:1313-1320

Etchegaray JB, Nishida T (1975) Biology of Lespesia archippivora (Diptera: Tachinidae). Proc Hawaii Entomol Soc 22:41-49

Geest EA (2017) Recruitment, survival, and parasitism of monarch butterflies (Danaus plexippus) in residential gardens and conservation areas. Thesis, University of Nebraska Omaha

Grace ES (1997) The world of the monarch butterfly. Sierra Club Books, California

Graham B (2017) Monarch butterflies migrating from Mexico visit KC early. Missouri Department of Conservation. https://mdc. mo.gov/newsroom/monarch-butterflies-migrating-mexico-visit -kc-early. Accessed 1 Aug 2017

Gustafsson KM, Agrawal AA, Lewenstein BV, Wolf SA (2015) The monarch butterfly through time and space: the social construction of an icon. Bioscience 65:612-622

Howard E, Davis AK (2015) Investigating long-term changes in the spring migration of monarch butterflies (Lepidoptera: Nymphalidae) using 18 years of data from Journey North, a citizen science program. Ann Entomol Soc Am 108:664-669

Janzen DH, Hallwachs W (2009) Dynamic database for an inventory of the macrocaterpillar fauna, and its food plants and parasitoids. Are de Conservacion Guanacaste (ACG), northwestern Costa Rica. http://janzen.sas.upenn.edu. Accessed 10 Dec 2016

Jepsen S, Schweitzer DF, Young B, Sears N, Ormes M, Black SH (2015) Conservation status and ecology of the monarch butterfly in the United States. NatureServe, Virginia, and the Xerces Society for Invertebrate Conservation, Oregon

Journey North (2017) Spring migration archives. Journey North: Monarch Butterfly. http://www.learner.org/jnorth/tm/monarch/ MigrationMaps.html. Accessed 19 May 2017

Kaul RB, Sutherland D, Rolfsmeier S (2011) The flora of Nebraska, 2nd edn. School of Natural Resources, University of Nebraska Lincoln, Nebraska

Kuznetsova A, Brockhoff PB, Christensen RHB (2017) "ImerTest" Package: tests in linear mixed effects models. J Stat Softw 82:1-26. https://doi.org/10.18637/jss.v082.i13

Levy JM, Connor EF (2004) Are gardens effective in butterfly conservation? A case study with the pipevine swallowtail, Battus philenor. J Insect Conserv 9:323-330

Lindsey E, Mehta M, Dhulipala V, Oberhauser K, Altizer S (2009) Crowding and disease: effects of host density on response to infection in a butterfly-parasite interaction. Ecol Entomol 34:551-561

Maeckle M (2016) At least 1.5 million monarch butterflies perish in deadly ice storm in Michoacán. Texas Butterfly Ranch. http://texasbutterflyranch.com/2016/03/13/at-least-1-5-millionmonarch-butterflies-perish-in-deadly-ice-storm-in-michoacan/. Accessed 19 May 2017

Majewska AA, Sims S, Wenger SJ, Davis AK, Altizer S (2018) Do characteristics of pollinator-friendly gardens predict the diversity, abundance, and reproduction of butterflies? Insect Conserv Divers 11:370-380. https://doi.org/10.1111/icad.12286

Malcolm SB (1991) Cardenolide-mediated interactions between plants and herbivores. In: Berenbaum MR, Rosenthal GA (eds) Herbivores: their interactions with secondary plant metabolites. Academic Press, New York, pp 251-296 
Marini L, Zalucki MP (2017) Density-dependence in the declining population of the monarch butterfly. Sci Rep 7:13957. https:// doi.org/10.1038/s41598-017-14510-w

McLaughlin RE, Myers J (1970) Ophryocystis elektroscirrha sp. n. a neogregarine pathogen of the monarch butterfly Danaus plexippus (L.) and the Florida queen butterfly Danaus gilippus berenice (Cramer). J Protozool 17:300-305

Mueller EK, Baum KA (2014) Monarch-parasite interactions in managed and roadside prairies. J Insect Conserv 18:847-853. https ://doi.org/10.1007/s10841-014-9691-z

Muratet A, Fontaine B (2014) Contrasting impacts of pesticides on butterflies and bumblebees in private gardens in France. Biol Conserv 182:148-154

Nail KR, Stenoien C, Oberhauser KS (2015) Immature monarch survival: effects of site characteristics, density, and time. Ann Entomol Soc Am 108:680-690

Nguyen J (2017) Milkweeds for monarchs. NEBRASKAland 95:52-53

O'Hara JE (2013) Tachinids of Bertha Armyworm: Lespesia. Tachinidae Resources. http://www.nadsdiptera.org/Tach/Nearctic/Berth a/Lesp.html. Accessed 30 Nov 2015

Oberhauser K (2004) Overview of monarch breeding biology. In: Oberhauser KS, Solensky MJ (eds) The monarch butterfly: biology and conservation. Cornell University Press, Ithaca, pp 3-8

Oberhauser K (2012) Tachinid flies and monarch butterflies: citizen scientists document parasitism patterns over broad spatial and temporal scales. Am Entomol 58:19-22

Oberhauser K, Kuda K (1997) A field guide to monarch caterpillars (Danaus plexippus). Department of Ecology, Evolution and Behavior; University of Minnesota, Minnesota

Oberhauser KS, Prysby MD, Mattila HR, Stanley-Horn DE, Sears MK, Dively G, Olson E, Pleasants JM, Lam WF, Hellmich RL (2001) Temporal and spatial overlap between monarch larvae and corn pollen. Proc Natl Acad Sci 21:11913-11918

Oberhauser K, Gebhard I, Cameron C, Oberhauser S (2007) Parasitism of monarch butterflies (Danaus plexippus) by Lespesia archippivora (Diptera: Tachinidae). Am Midl Nat 157:312-328

Oberhauser KS, Cotter D, Davis D, Décarie R, Behnumea AE, GalinoLeal C, Gallina Tessaro MP, Howard E, Lauriault J, Maczieski W, Malcolm S, Martínez F, González JM, McRae M, Nernberg D, Pisanty-Baruch I, Ramírez I, Reyes JJ, Wilson V (2008) North American monarch conservation plan. Commission for Environmental Cooperation, Montreal

Oberhauser KS, Batalden R, Howard E (2009) Monarch monitoring in North America: overview of initiatives and protocols. Commission on Environmental Cooperatio, Montreal

Oberhauser K, Elmquist D, Perilla-López J, Gebhard I, Lukens L, Sitreman J (2017a) Tachinid fly (Diptera: Tachninidae) parasitoids of Danaus plexippus (Lepidoptera: Nymphalidae). Ann Entomol Soc Am 110:536-543

Oberhauser KS, Wiederholt R, Diffendorfer JE, Semmens D, Ries L, Thogmartin WE, Lopez-Hoffman L, Semmens B (2017b) A transnational monarch butterfly population model and implications for regional conservation priorities. Ecol Entomol 42:51-60

Oyeyele SO, Zalucki MP (1990) Cardiac glycosides and oviposition by Danaus plexippus on Asclepias fruticosa in south-east Queensland (Australia), with notes on the effect of plant nitrogen content. Ecol Entom 15:177-185

Panella M (2017) Conservation strategy for monarchs (Danaus plexippus) and at-risk pollinators in Nebraska. Nebraska Monarch and pollinator Initiative, Nebraska Game and Parks Commission, Nebraska

Pitman G (2017) Patterns and causes of oviposition in monarch butterflies: implications for milkweed restoration. Thesis, University of Georgia
Pleasants JM, Oberhauser KS (2013) Milkweed loss in agricultural fields because of herbicide use; effect on the monarch butterfly population. Insect Conserv Divers 6:135-144. https://doi.org/10. 1111/j.1752-4598.2012.00196.x

Pleasants JM, Zalucki MP, Oberhauser KS, Brower LP, Taylor OR, Thogmartin WE (2017) Interpreting surveys to estimate the size of the monarch butterfly population: pitfalls and prospects. PLoS ONE 12(7): e0181245. https://doi.org/10.1371/journ al.pone. 0181245

Prysby MD (2004) Natural enemies and survival of monarch eggs and larvae. In: Oberhauser KS, Solensky MJ (eds) The monarch butterfly: biology and conservation. Cornell University Press, Ithaca, pp 27-37

R Core Team (2016) R: A language and environment for statistical computing. R Foundation for Statistical Computing, Vienna, Austria. http://www.R-project.org/. Accessed 13 Feb 2016

Rasmann S, Agrawal A (2011) Latitudinal patterns in plant defense: evolution of cardenolides, their toxicity and induction following herbivory. Ecol Lett 14:476-483

Rawlins JE, Lederhouse RC (1981) Developmental influences of thermal behavior on monarch caterpillars (Danus plexippus): an adaptation for migration (Lepidoptera: Nymphalidae: Danainae). J Kansas Entom Soc 54:387-408

Satterfield DA, Maerz JC, Alitzer S (2015) Loss of migratory behavior increases infection risk for a butterfly host. Proc R Soc B 282:20141734. https://doi.org/10.1098/rspb.2014.1734

Schaffner JV, Griswold CL (1938) Macrolepidoptera and their parasites reared from field collections in the northeastern part of the United States. United States Department of Agriculture Misc. Pub. No. 188

Shahani PC, del Río Pesado G, Schappert P, Serrano EG (2015) Monarch habitat conservation across North America: past progress and future needs. In: Oberhauser KS, Nail KR, Alitzer S (eds) Monarchs in a changing world: biology and conservation of an iconic butterfly. Cornell University Press, Ithaca, pp 31-41

Stenoien C, Nail KR, Li J, Oberhasuer KS (2015) Habitat productivity and temporal patterns of monarch butterfly egg densities in the Eastern United States. Ann Entomol Soc Am 108:670-679

Stenoien C, Nail KR, Zalucki JM, Parry H, Oberhauser KS, Zalucki MP (2018) Monarchs in decline: a collateral landscape-level effect of modern agriculture. Insect Sci 25:528-541

Taylor OR (2017) Monarch waystation program. MonarchWatch. http:// www.monarchwatch.org/waystations/. Accessed 17 July 2017

Therneau TM (2016) Package survival. R Foundation for Statistical Computing, Vienna

Tooker JF, Hauser M, Hanks LM (2006) Floral host plants of syrphidae and tachinidae (diptera) of central Illinois. Ann Entomol Soc Am 99:96-112

Urquhart FA (1998) The monarch butterfly: international traveler. Wm. Caxton Ltd., Wisconsin

USDA (2017) Monarch butterfly: what is citizen science? USDA: Forest Service. https://www.fs.fed.us/wildflowers/pollinators/Monar ch_Butterfly/do/index.shtml. Accessed 14 Feb 2017

Ward E (2014) Milkweeds for monarchs: the St. Louis butterfly project. St. Louis-Missouri. https://www.stlouis-mo.gov/monarchs/. Accessed 15 Feb 2017

Wood DM (1987) Chap. 110. Tachinidae. In: McAlpine JF, Peterson BV, Shewell GE, Teskey HJ, Vockeroth JR, Wood DM (eds) Manual of nearctic diptera vol. 2. Agriculture Canada Monograph, NRC Research Press, Ottawa, pp 1193-1269

Zalucki MP (1981) Temporal and spatial variation of parasitism in Danaus plexippus (L.) (Lepidoptera: Nymphalidae: Danainae). Aust Entomol Mag 8:3-8

Zalucki MP (1982) Temperature and rate of development in Danaus plexippus L. and D. chrysippus L. (Lepidoptera: Nymphalidae). J Aust Ent Soc 21:241-246 
Zalucki MP, Brower LP (1992) Survival of first instar larvae of Danaus plexippus (Lepidoptera: Danainae) in relation to cardiac glycoside and latex content of Asclepias humistrata (Asclepiadaceae). Chemoecology 3:81-93

Zalucki MP, Kitching RL (1982a) Dynamics of oviposition in Danaus plexippus (Insecta: Lepidoptera) on milkweed Asclepias spp. J Zool Lond 198:103-116

Zalucki MP, Kitching RL (1982b) Temporal and spatial variation of mortality in field populations of Danaus plexippus L. and $D$. chrysippus L. Larvae (Lepidoptera: Nymphalidae). Oecologia 53:201-207

Zalucki MP, Lammers JH (2010) Dispersal and egg shortfall in Monarch butterflies: what happens when the matrix is cleaned up? Ecol Entom 35:84-91

Zalucki MP, Suzuki Y (1987) Milkweed patch quality, adult population structure, and egg laying in the monarch butterfly. J Lepidopterists' Soc 41:13-22
Zalucki MP, Brower LP, Malcolm SB (1990) Oviposition by Danaus plexippus in relation to cardenolide content of three Asclepias species in southeastern U.S.A. Ecol Entom 15:231-240

Zalucki MP, Brower LP, Alonso-M A (2001a) Detrimental effects of latex and cardiac glycosides on survival and growth of first-instar monarch butterfly larvae Danaus plexippus feeding on the sandhill milkweed Asclepias humistrata. Ecol Entomol 26:212-224

Zalucki MP, Malcolm SB, Paine TD, Hanlon CC, Brower LP, Clarke AR (2001b) It's the first bites that count: survival of first-instar monarchs on milkweed. Austral Ecol 26:547-555

Zalucki MP, Parry HR, Zalucki JM (2016) Movement and egg laying in monarchs: to move or not to move, that is the question. Austral Ecol 41:154-167

Zeileis A, Hothorn T (2002) Diagnostic checking in regression relationships. R News 2:7-10. https://CRAN.R-project.org/doc/Rnews . Accessed 18 June 2018 